Ethiopian Journal of Environmental Studies \& Management 10(3): 404 - 414, 2017.

ISSN:1998-0507

doi: https://dx.doi.org/10.4314/ejesm.v10i3.10

Submitted: January 13, 2017

Accepted: May 03, 2017

\title{
ROLE OF AGRICULTURAL ENTERPRISES IN FOOD SECURITY STATUS OF URBAN FARMERS IN IKORODU METROPOLIS, LAGOS STATE, NIGERIA
}

*EDEOGHON, C.O. AND IDOWU, A.A.

Department of Agricultural Economics and Extension Services, Faculty of Agriculture, University of Benin, P.M.B. 1154, Nigeria

\begin{abstract}
The study examined the role of agricultural enterprises in food security status of urban farmers in Ikorodu metropolis. Using a multistage technique, 150 urban farmers were selected and surveyed with a structured questionnaire. Data was subjected to simple descriptive statistics and Spearman rank correlation co-efficient was used to test the hypothesis. Most of the urban farmers (60\%) were females with average age of 42 years of an average household size of 7 persons having a mean monthly income of $\$ 22,900.00$. Food security mean score of urban farmers was 2.73 indicating food secure without hunger. Relationship between food security and agricultural enterprises reveal the tendency of fruits, vegetables and fisheries as moving urban farmers towards food secure group. It was recommended that urban farmers concentrate more on the fruit production enterprise, vegetable enterprise and fisheries enterprises to attain food secure groups.
\end{abstract}

Key Words: Urban farming enterprises, Food security, Ikorodu, Lagos State

\section{Introduction}

United Nations (1988) stated that urban agriculture is an age-long practice that was developed to neutralize the challenges imposed by the growing human population, especially in the urban areas. According to this report, urban agriculture is practiced on small to medium sized areas within the city for growing annual food crops, raising livestock and fish for home consumption or sale. The practice of urban agriculture is carried out in vacant plots, in home gardens, on verges, in containers, on balconies, on roof tops, in school gardens, on open spaces, on road strips, below railways lines, below power lines, along river banks, on communal land etc.

Food security is the state achieved when food system operates such that "all the people, at all times, have physical and economic access to sufficient, safe and nutritious food to meet their dietary needs and food preferences for an active and healthy life (FAO, 2001). The main goal of food security is for individuals to be able to obtain adequate food needed at all times, and to be able to utilize the food to meet the body's needs. Food security is multifaceted. The World Bank (2001) identified three pillars underpinning food security; these are food availability, food accessibility, and food utilization. This

*Corresponding Author: Edeoghon, C.O. 
infers from the concept that food security is not just a production issue. Food security diminishes when food system is stressed. The pillars of food security with their elements are as follows: food availability: Production, distribution, exchange food accessibility: affordability, allocation, preference food utilization: nutritional value, social value, food safety, food availability for the farm household means ensuring sufficient food is available for them through their own production. However, due to lack of adequate storage facilities and pressing needs, they mostly end up selling excess produce during the harvesting period, and sometimes rely on market purchases during the hungry season.

Food accessibility means reducing poverty. This is because simply making food available is not enough; one must also be able to purchase it, especially the low-income households (Sen, 1981). Food utilization means ensuring a good nutritional outcome, which is nutrition security. Having sufficient food will not ensure a good nutritional outcome if poor health results in frequent sickness. Building this pillar means investing in complementary resources such as nutrition education, health care, provision of safe water and better sanitation, instituting gender symmetry, and removal of child abuse practices (Obamiro, Doppler and Kormawa (2007). Pillars of food security can be summarized with equation below:

Food security=food availability+food accessibility+food utilization, where Availability $=$ sufficient food for the farm household

Accessibility $=$ affordability and good road networks to the market for sales and purchase
Utilization $=$ good nutritional outcomes .

According to the final declaration of World Forum on Food Sovereignty (WFFS) by Nyeleni (2007), food security is the people's right to define their own policies and strategies for sustainable production, distribution and consumption of food that guarantees the right to food for the entire population, on the basis of small and medium sized production respecting their own cultures and diversity of peasant, fishing and indigenous forms of agricultural production, marketing and management of rural areas, in which women play a fundamental role. This declaration points to the importance of food security and its position in maintaining a healthy household and society.

Food insecurity exists when people are undernourished as a result of physical unavailability of food, lack of social and economic access to adequate food and/or inadequate food utilization. To curb the issue of food insecurity, the United Nations came to a consensus to create the Food and Agriculture Organization (FAO), in October 16, 1945 with the primary objective to 'defeat' hunger. This is reflected on its Latin motor "Fiat panis" meaning "Let there be bread".

However, for the purpose of this study only two pillars of food security (food availability and food accessibility) will be examined in the study area due to limitations of resources. On this note, the study examined the socio-economic characteristics of urban farmers, identified the agricultural enterprises, and examined the food security status of the urban farmers in the study area. 


\section{Methodology}

The study was conducted in Ikorodu LGA of Lagos State, Nigeria using a multistage sampling technique and Ikorodu was purposively selected it is highly dominated by agricultural activities. Also, it is the $7^{\text {th }}$ largest of the 20 LGAs with a population of 535,071 (NPC, 2006) having a climatic condition that favours the growth of tropical plants and crops such as cassava, vegetables and maize. At the second stage, five (5) communities (Igbogbo, Bayeku, Itamga, Ewu-Elepe, Imota and Odoungunyan) were purposively selected based on the intensity of farming activities in the local government while the third stage of selection involved a simple random selection of thirty (30) urban farmers from each of the communities to make up a total of one hundred and fifty respondents in the study area. Data were collected using a well-structured questionnaire through field survey and farmers interview. Secondary data were from relevant literature works and existing documents.
Descriptive statistics such as frequency counts and percentages, mean and standard deviation were used to analyze the socio-economic characteristics of the urban farmers. Inferential statistics such as Spearman rank correlation co-efficient was used to test the hypothesis.

r

where $\mathrm{d}=\mathrm{X}-\mathrm{Y}$ (deviations $=$ differences between the ranks of each observation on the 2 variables)

$\mathrm{n}=$ sample size

$\mathrm{X}=$ independent variable

$\mathrm{Y}=$ dependent variable.

The food security status of the respondents was analyzed using the United State Department of Agriculture (USDA) International food security code module. This uses a range from zero (0) to (10) as described below.

USDA International Food Security Code Module

Urban farmers with scale value 0 are regarded as food secure while values scaling toward 10 are regarded as food insecure with varying levels of severity. 
Table1: Households with complete responses: Food security scale values and status levels corresponding to number of affirmative responses

\begin{tabular}{|c|c|c|c|c|}
\hline \multicolumn{2}{|c|}{$\begin{array}{l}\text { Number of Affirmative } \\
\text { Responses: }\end{array}$} & \multirow[t]{2}{*}{$\begin{array}{l}1998 \text { Food } \\
\text { Security } \\
\text { Scale Values a } \\
\end{array}$} & \multicolumn{2}{|c|}{ Food Security Status Level } \\
\hline $\begin{array}{l}\text { (Out of 18) } \\
\text { Households } \\
\text { With } \\
\text { Children }\end{array}$ & \begin{tabular}{|l} 
(Out of 10) \\
Households \\
Without \\
Children
\end{tabular} & & Code & Category \\
\hline $\begin{array}{l}0 \\
1 \\
2\end{array}$ & $\begin{array}{l}0 \\
1 \\
2\end{array}$ & $\begin{array}{l}0.0 \\
1.0 \\
1.2 \\
1.8 \\
2.2\end{array}$ & 0 & Food Secure \\
\hline \begin{tabular}{|l}
3 \\
4 \\
5 \\
6 \\
7
\end{tabular} & 4 & $\begin{array}{l}2.4 \\
3.0 \\
3.0 \\
3.4 \\
3.7 \\
3.9 \\
4.3 \\
4.4 \\
\end{array}$ & 1 & $\begin{array}{ll}\text { Food } & \text { Insecure } \\
\text { Without } & \text { Hunger }\end{array}$ \\
\hline \begin{tabular}{|l}
8 \\
9 \\
10 \\
11 \\
12
\end{tabular} & $\begin{array}{l}6 \\
7 \\
8 \\
9\end{array}$ & $\begin{array}{l}4.7 \\
5.0 \\
5.1 \\
5.5 \\
5.7 \\
5.9 \\
6.3 \\
6.4\end{array}$ & 2 & $\begin{array}{l}\text { Food Insecure With } \\
\text { Hunger, Moderate }\end{array}$ \\
\hline \begin{tabular}{|l}
13 \\
14 \\
15 \\
\\
16 \\
17 \\
18 \\
\end{tabular} & 9 & $\begin{array}{l}6.6 \\
7.0 \\
7.2 \\
7.4 \\
7.9 \\
8.0 \\
8.7 \\
9.3 \\
\end{array}$ & 3 & $\begin{array}{l}\text { Food Insecure With } \\
\text { Hunger } \\
\text { Severe }\end{array}$ \\
\hline
\end{tabular}

Source: USDA International Food Security Code Module (2015)

\section{Results and Discussion}

Agricultural Enterprises Engaged in by the Urban Farmers

Table 2 shows various agricultural enterprises urban farmers engaged in the study area. The result showed a regular participation of urban farmers in grains production $(\mathrm{M}=2.36)$, fruit production $(\mathrm{M}=2.31)$, vegetable enterprise $(\mathrm{M}=$ 2.29) and tuber crops $(\mathrm{M}=2.50)$. The table also showed that urban farmers rarely participate in cash crop production $(\mathrm{M}=1.24)$ especially on a subsistence level. A number of studies (NRI, 1999; 
Mireri, 2002) attributed this observation to limited area of land for agricultural purpose, huge capital for establishment, long gestation period, and high level of technical management, seasonality of production, inadequate market and incidence of pests and diseases for cash crops enterprises. The result (from the table) also showed regular participation in poultry production $(\mathrm{M}=2.60)$, rabittery $(\mathrm{M}=2.40)$, fishery $(\mathrm{M}=2.24)$, snailery $(\mathrm{M}=2.37)$ and grasscutter enterprises $(\mathrm{M}=2.22)$. The regular participation in poultry, rabittery, and fishery can be linked to their socio-cultural and economic importance in urban food demand in the study area.

The dispersions around means for grains production $(2.36 \pm 0.2)$, fruit crop production $\quad(2.31 \pm 0.3), \quad$ vegetable enterprise $(2.29 \pm 0.2)$, tuber crops $(2.50 \pm 0.4)$ and root crops enterprises $(2.36 \pm 0.1)$ as well as poultry production $(2.60 \pm 0.5)$, rabittery $(2.40 \pm 0.2)$, snailery $(2.37 \pm 0.30)$ and grasscutter production $(2.22 \pm 0.2)$ are very small and hence, do not affect the significance of the means. However, the dispersions around mean for cash crops enterprise and ruminants are very large therefore affect the significance of the means. This findings confirmed that of Semwanga (2000) who observed in his study of urban agriculture that many of the urban residents practice agricultural activities ranging from horticultural crops (fruits, vegetables and flowers); root tubers (cassava, yams, sweet potatoes), legumes and cereals; livestock farming (cattle, poultry, pigs and goats) and some paddy rice fields in the swampy areas. The result was also similar to that obtained by Ibadan Multistakeholder team (2007) when they observed that over $73 \%$ of urban dwellers in Ibadan city participated in food crop production such as vegetables, grains, roots, tubers, floriculture and fruit crops production. They also observed that less than $4 \%$ engaged in ruminant production while the rest practice aquaculture (majorly fishery), poultry, snailery, bee keeping (apiculture) and sericulture (silk worm rearing). FAO (2007) also identified regular agricultural enterprises in urban areas to include the production of different of crops (grains, root crops, vegetables, tubers crops, fruits, cash crops, mushrooms, oil crops) and/or animals (poultry, rabbits, goats, sheep, cattle, pigs, guinea pigs, fish, earthworms, bees etc) or combination of them. However, Mwangi (1995) identified limited access to land as a major constraint to the choice of urban agricultural enterprise, hence urban dwellers tend to engage in production activities that demand less space, little management practices, short production season, quick sale of produce and small start-up capital. The finding of ArmarKlemesu (2000) in his study on urban agriculture and food security, nutrition and health, justified this result when he observed that in many cities urban agriculture provides a substantial part of the urban demand for vegetables, fresh milk, poultry and eggs, food crops, fruits and freshwater fish and to a lesser extent, pigs, ruminants and grasscutter which met less than $15 \%$ of urban food demand. 
Role of Agricultural Enterprises in Food Security...............EDEOGHON \& IDOWU

Table 2: Agricultural Enterprises involved in by respondents

\begin{tabular}{lllllllll}
\hline Enterprise & Always & \multicolumn{3}{l}{ Sometimes } & \multicolumn{2}{l}{ Not at all } & Total \\
\hline & Freq & $\%$ & Freq & $\%$ & Freq & $\%$ & Mean & S.D \\
\hline Grains & 70 & 46.7 & 64 & 42.7 & 16 & 10.7 & $2.36^{*}$ & 0.2 \\
Fruits & 68 & 45.3 & 60 & 40.0 & 22 & 14.7 & $2.31^{*}$ & 0.3 \\
Vegetables & 65 & 43.3 & 62 & 41.3 & 23 & 15.3 & $2.29^{*}$ & 0.2 \\
Tubers & 82 & 54.7 & 60 & 40.0 & 8 & 5.3 & $2.51^{*}$ & 0.4 \\
Root crops & 64 & 42.7 & 70 & 46.7 & 16 & 10.7 & $2.36^{*}$ & 0.1 \\
Cash crops & 14 & 9.3 & 8 & 5.3 & 128 & 85.3 & 1.24 & 0.9 \\
Ruminants & 30 & 20.0 & 23 & 15.3 & 97 & 64.7 & 1.55 & 0.8 \\
Snailery & 69 & 46.0 & 67 & 44.7 & 14 & 9.3 & $2.37^{*}$ & 0.3 \\
Poultry & 110 & 73.3 & 30 & 20.0 & 10 & 6.7 & $2.60 *$ & 0.5 \\
Piggery & 5 & 3.3 & 3 & 2.0 & 142 & 94.7 & 1.09 & 0.8 \\
Rabbitery & 80 & 53.3 & 26 & 17.3 & 44 & 29.3 & $2.40^{*}$ & 0.2 \\
Grasscutter & 70 & 46.7 & 40 & 26.7 & 40 & 26.7 & $2.22^{*}$ & 0.2 \\
Fishery & 67 & 44.7 & 52 & 34.7 & 31 & 20.7 & $2.24^{*}$ & 0.2 \\
\hline
\end{tabular}

*Regular enterprises $=$ Mean $\geq 2.0$

\section{Factors that Contribute to Food Insecurity among Urban Farmers}

Table 3 shows the ranking of factors that contribute to food insecurity among urban farmers in the study area in the order of relevance (magnitude). It was obvious from the Table that high cost of food $(\mathrm{M}=3.12)$, low soil fertility $(\mathrm{M}=$ 3.09) and limited area of land $(\mathrm{M}=3.04)$ were the strongest reason why urban farmers in the study area could not attained food security. Garrett (2000) observed that high per unit cost of food during off-season limit the ability of farmers to access wholesome food from the market. FAO also noted that price of food that surged by 57\% between March 2007 and March 2008 had created negative implications for households food security, especially for the poor urban farmers (FAO, 2008). Maxwell (1996) also viewed that prices of food will keep rising because of increasing demand from urban population. $\mathrm{He}$ suggested that adequate storage and preservation will keep urban farmers from the effect of inflation of food prices. Inadequate access to land was also found to influence food security among farmers in urban areas as this limit production capacity greatly. Mawoneke and King (2005) observed that potential urban land is viewed as a tradable commodity that competes with other land uses. This therefore limits participation of urban dwellers in urban agriculture.

The study (from the Table) also showed that low capital $(\mathrm{M}=2.99)$, lack of innovation $(\mathrm{M}=2.94)$, distant market $(\mathrm{M}=2.87)$, poor storage $(\mathrm{M}=2.80)$, poor processing $(\mathrm{M}=2.55)$, irregular climate $(\mathrm{M}=2.79)$ and low level of education $(M=2.75)$ moderately contribute to food insecurity among the farmers. Low access to adequate capital at the right time continued to inhibit urban farmers from expanding their production, hence low level of income and food insecurity. Low level of innovation or research into urban agriculture also limits the potentials of urban agriculture in meeting its objectives. The adoption of innovative approach into urban agriculture of Havana, Cuba proved that urban 
agriculture can help urban farmers attain food security (Cuba Ministry of Agriculture, 2008).

The dispersions from the means for low capital $(2.99 \pm 0.48)$, no level of innovation (2.94 \pm 0.71$)$, irregular climate
$(2.79 \pm 0.70)$, large family size $(2.73 \pm 0.61)$ and poor processing facility $(2.55 \pm 0.18)$ are very small and hence, do not affect the significance of he means; indicating serious hindrances to food security.

Table 3: Factors contributing to food insecurity among urban farmers

\begin{tabular}{|c|c|c|c|c|c|c|c|c|c|c|}
\hline \multirow[t]{2}{*}{ Factors } & \multicolumn{2}{|c|}{ Very high } & \multicolumn{2}{|c|}{ High } & \multicolumn{2}{|c|}{ Low } & \multicolumn{2}{|c|}{ Very low } & \multicolumn{2}{|c|}{ Total } \\
\hline & Freq & $\%$ & Freq & $\%$ & Freq & $\%$ & Freq & $\%$ & Mean & SD \\
\hline High cost of food & 90 & 60 & 20 & 13.3 & 10 & 6.7 & 30 & 20 & $3.13^{*}$ & 0.62 \\
\hline Low soil fertility & 80 & 53.3 & 30 & 20 & 18 & 12 & 22 & 14.7 & $3.12 *$ & 0.21 \\
\hline Small area of land & 54 & 36 & 61 & 40.7 & 23 & 15.3 & 12 & 8 & $3.04 *$ & 0.3 \\
\hline Low capital & 70 & 46.7 & 26 & 17.3 & 37 & 24.7 & 17 & 11.3 & $2.99 *$ & 0.48 \\
\hline No technology & 58 & 38.7 & 42 & 28 & 33 & 22 & 17 & 11.3 & $2.94 *$ & 0.71 \\
\hline Distant market & 62 & 41.3 & 22 & 14.7 & 50 & 33.3 & 16 & 10.7 & $2.87 *$ & 0.99 \\
\hline Poor storage & 44 & 29.3 & 50 & 33.3 & 38 & 25.3 & 18 & 12 & $2.80 *$ & 0.9 \\
\hline Irregular climate & 50 & 33.3 & 38 & 25.3 & 43 & 28.7 & 19 & 12.7 & $2.79 *$ & 0.7 \\
\hline Large family & 40 & 26.7 & 60 & 40 & 20 & 13.3 & 30 & 20 & $2.73 *$ & 0.61 \\
\hline Poor processing & 27 & 18 & 70 & 46.7 & 12 & 8 & 41 & 27.3 & $2.55^{*}$ & 0.18 \\
\hline
\end{tabular}

*strong factors (mean $>=2.50$ )

\section{Food Security Status of Urban Farmers}

Table 4 shows the food security status of respondents in the study area. It was observed that only $16.7 \%$ of the respondents were food secure, $52 \%$ were food insecure without hunger, 19.3\% were food insecure with hunger while $12 \%$ were food insecure with severe hunger. Figure 2 below gives a detailed description of the food security status of the respondents.

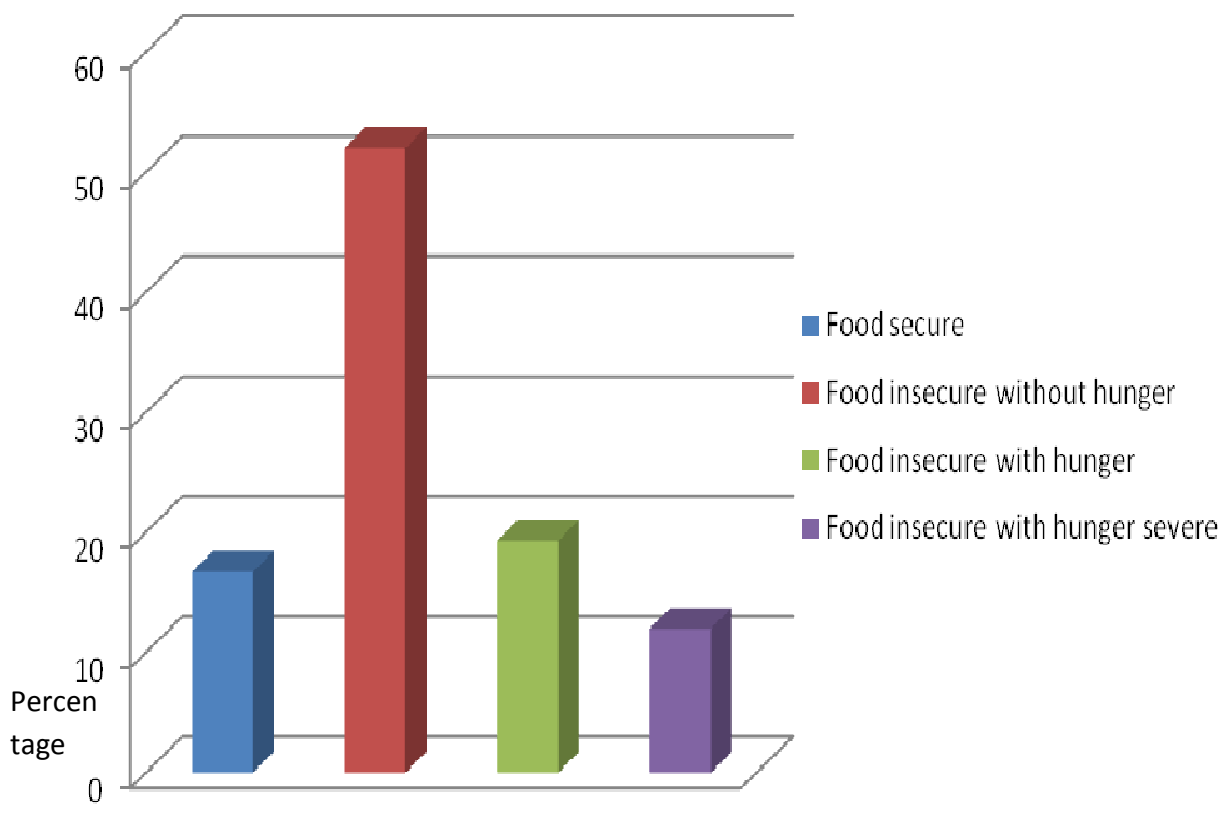

Figure 2: Food security status of respondent 
The mean score of food security status was 2.73. This score value falls within the food insecure without hunger range i.e. 2.40-4.40 on USDA food security scale. This means that an average urban farmer in the study area was food insecure without hunger. This result is similar to that obtained in a study by the Noguchi Memorial Institute for Medical Research (NMIMR) in Ghana (ArmarKlemesu et al., 1998) where they observed little measurable impact of urban agriculture on consumption or overall food security. They concluded that urban agriculture in developing nations has potential of eradicating the challenge of extreme hunger among the farmers but food security is far from being attained. According to Che and Chen (1999) in their work on food insecurity among farmers in Canadian households, about 1 in 10 Canadian farmers was food-insecure in 1998/99. Compromised diets were particularly common among low-income urban farmer households; this was a regular characteristic of food insecure without hunger group according to USDA stratification. They also noted that food insecurity was associated with both physical and emotional health problems.
Maxwell (1995) and Mwangi (1995) concluded from their studies that even if the proportion of total household access to food from home production is small, part of the importance of semisubsistence strategies was that the household can access this food at critical times, such as when income was insufficient for food purchases, or can access foods that add to dietary diversity. This suggests that although the farmers have not attained complete food security, urban agriculture contributes in no small measure to their sustenance and urban livelihood.

Several factors pointed earlier contributed to food insecurity among the farmers. The most significant among these factors were completely beyond the control of the urban farmers, they were challenges imposed by failing policies and inadequate structural adjustment in relation to urban agriculture sub-sector. It was earlier noted that food insecurity was significantly influenced by high per unit cost of food especially during the offseason. The prices of food are determined by uncontrollable forces of demand and supply that cannot be regulated by individual unit of consumers.

Table 4: Food security status of respondents $(\mathrm{N}=150)$

\begin{tabular}{llllc}
\hline Status & Frequency & Percent & Range & Mean score \\
\hline Food secure & 25 & 16.7 & $0.0-2.2$ & \\
Food insecure without hunger & 78 & 52 & $2.4-4.4$ & 2.73 \\
Food insecure with hunger & 29 & 19.3 & $4.7-6.7$ & \\
Food insecure with hunger severe & 18 & 12 & $6.6-9.3$ & \\
\hline
\end{tabular}

\section{Relationship between Respondents' Food Security Status and Their Agricultural Enterprises}

Table 5 shows that there exist a positive and significant correlation between the food secure group and enterprises of fruit production enterprise $(\mathrm{r}=0.252, \mathrm{p}=0.0231)$, vegetable enterprises $(r=0.0311, p=0.0221)$, and fishery enterprises $(r=0.231, p=0.011)$. 
This indicated that these enterprises moved the farmers towards food secure group. This implied that majority of the food secure participated in these enterprises. The table also showed that food-insecure-without hunger group was positively and significantly correlated with grains production $(\mathrm{r}=0.25, \mathrm{p}=$ $0.0120)$, tubers crops enterprises $(\mathrm{r}=$ $0.204, p=0.041)$, cash crop enterprise ( $\mathrm{r}$ $=0.211, \mathrm{p}=0.013)$ and piggery enterprise $(r=0.222, p=0.038)$.

The study (from the table) also showed that there exist a negative but significant correlation between food- secure-with-hunger group and vegetable enterprise $(\mathrm{r}=-0.230, \mathrm{p}=0.009)$, tuber crops $(\mathrm{r}=-0.209, \mathrm{p}=0.042)$ and poultry enterprise $(\mathrm{r}=-0.201, \mathrm{p}=0.0078)$. This means that increase in participation in these enterprises move urban farmers out of this group towards food secure group. The result also showed a significant but negative relationship between food insecure with severe hunger group and grain production enterprise $(\mathrm{r}=-0.215, \mathrm{p}$ $=0.005)$, root crops enterprises $(\mathrm{r}=-$ $0.183, \mathrm{p}=0.049)$ and snailery production $(\mathrm{r}=-0.630, \mathrm{p}=0.0153)$.

Table 5: Relationship between respondents' food security status and their agricultural enterprises $(\mathrm{N}=150)$

\begin{tabular}{lllllllll}
\hline Enterprise & \multicolumn{2}{c}{ Food secure } & \multicolumn{2}{c}{$\begin{array}{c}\text { Food } \\
\text { insecure-hunger }\end{array}$} & \multicolumn{2}{c}{$\begin{array}{c}\text { Food } \\
\text { insecure+hunger }\end{array}$} & \multicolumn{2}{c}{$\begin{array}{c}\text { Food insecure }+ \\
\text { hunger severe }\end{array}$} \\
& $\mathrm{r}$ & Prob. & $\mathrm{r}$ & Prob. & $\mathrm{r}$ & Prob. & $\mathrm{r}$ & Prob. \\
Grains & 0.04 & 0.73 & $0.250^{*}$ & 0.01 & -0.01 & 0.82 & $-0.215^{*}$ & 0.01 \\
Fruits & $0.252^{*}$ & 0.02 & 0.02 & 0.12 & -0.04 & 0.88 & -0.09 & 0.66 \\
Vegetables & $0.311^{*}$ & 0.02 & 0.27 & 0.13 & $-0.230^{*}$ & 0.09 & -0.09 & 0.03 \\
Tubers & 0.01 & 0.99 & $0.204^{*}$ & 0.02 & $-0.209^{*}$ & 0.04 & -0.66 & 0.81 \\
Roots & 0.09 & 0.72 & -0.19 & 0.75 & -0.02 & 0.70 & $-0.183^{*}$ & 0.05 \\
Cash crops & 0.20 & 0.62 & $0.211^{*}$ & 0.01 & -0.13 & 0.10 & -0.09 & 0.65 \\
Snailery & 0.02 & 0.42 & 0.03 & 0.05 & -0.71 & 0.09 & $-0.633^{*}$ & 0.02 \\
Poultry & 0.05 & 0.33 & -0.05 & 0.88 & $-0.201 *$ & 0.05 & -0.01 & 0.07 \\
Piggery & 0.231 & 0.068 & $0.222^{*}$ & 0.038 & -0.18 & 0.66 & -0.331 & 0.089 \\
Fishery & $0.231^{*}$ & 0.011 & 0.119 & 0.627 & -0.53 & 0.57 & -0.63 & 0.153 \\
Grasscutter & 0.003 & 1.232 & 0.058 & 0.451 & 0.02 & 0.306 & -0.25 & 0.076 \\
\hline
\end{tabular}

*significant at $5 \%$ level (0.050)

\section{Conclusion}

The significant enterprises engaged in by respondents include grains, fruits, vegetables, snailery, poultry, and fishery production. The food security scale value was 2.73 which fall within ranges of food secure without hunger zone. This is an indication of moderate hunger. The relationship between food security and agricultural enterprises reveal the tendency of fruits, vegetables and fisheries as moving urban farmers towards food secure group.

\section{Recommendations}

1) Since urban farmers were food secure to a large extent, the government should implement policies that will encourage urban dwellers to participate in agriculture with the necessary inputs and infrastructure available 
such as markets. Operation Feed the Nation (OFN) and Green revolution is examples to consider.

2) Urban farmers should be encouraged to concentrate more on the fruit production enterprise, vegetable enterprise and fisheries enterprises to move them faster to food secure groups.

\section{References}

Armar-Klemesu, M. (2000). 'Urban Agriculture and Food Security, Nutrition and Health'. Growing Cities, Growing Food, Urban Agriculture on the Policy Agenda, Germany: Feldafing, 99-117.

Armar-Klemesu, M; Akpedonu, P; Egbi, G. and Maxwell, D. (1998). Food Contamination in Urban Agriculture: Vegetable Production Using Waste Water. In: ArmarKlemesu, M. and Maxwell, D. (eds), Urban Agriculture in Greater Accra Metropolitan Area: Report to IDRC. Legon: NMIMR.

Cuba Ministry of Agriculture. (2008). Cuba's Food Agriculture Situation Report. USDA.

FAO, (2001). 'A Briefing Guide for the Successful Implementation of Urban and Peri-urban Agriculture in developing Countries and Countries of Transition'. Revision, Handbook Series. Vol. III. Rome.

FAO (2007). Profitability and Sustainability of Urban and PeriAgriculture. FAO. Rome. 108 pp.

FAO, (2008). 'The State Of Food Insecurity in The world 2008: High Food Prices and Food Security Threats and Opportunities'. Rome: FAO.
Garrett, J.L. (2000). Achieving Urban Food and Nutrition Security in the Developing World. International Food Policy Research Institute, Washington D.C. 20pp.

Che, J. and Chen, J. (2001). "Food insecurity in Canadian Households", Health Reports, 12(4), Ottawa: Statistics Canada

Mawoneke, S. and King, B. (2005). Impact of Urban Agriculture Research in Zimbabwe: Cities Feeding People Programme of the IDRC.

Maxwell, D. (1995). 'Alternative Food Security Strategy: A Household Analysis of Urban Agriculture in Kampala.' World Development. Vol. 23(10), 1669-1681.

Maxwell, D. (1996). 'Alternative Food Security Strategy: A Household Analysis of Agriculture in Kampala'. World Development. 23 (10). 1669-1681.

Maxwell, D. (1999). 'Urban Food Security in Sub-saharan Africa for Hunger Proof Cities: Sustainable Urban Food Systems'. Ottawa: IDRC: 26-29.

Mireri, M. (2002). Private investment in urban agriculture in Nairobi, Kenya Urban Agriculture Magazine, no 7. August 2002. Economics of urban.

Mwangi, A. M. (1995). 'The Role of Urban Agriculture for Food Security in Low Income Areas in Nairobi.' FNSP Report 27 No. 54. Leiden: African Studies Centre

NPC, (2007). Advertorial- National Population Commission: Lagos State

NRI, (1999). Kumasi urban natural resources studies, 
KNUST/NRI/DFID. KNRMP report, R6799.

Nyeleni, O. (2007). World Food Sovereignty, Mali. Food Sovereignty Network: Aksel Neerstad, Development Fund. Pp 38.

Obamiro, E.O., Doppler, W. and Kormawa, P.M. (2007). Pillars of Food Security in Rural Areas of
Nigeria. Internet Forum of Food Africa (http://foodafrica.nri.org).

Sen, A. (1981). Poverty and Famines. An Essay on Entitlement and Deprivation. Oxford Clarendon Press.

World Bank (2001). strategy for Food Nutrition Security. World Bank Report. No 9040. Washinton. D.C. 